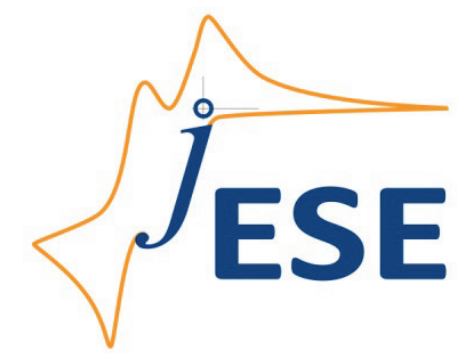

Open Access : : ISSN 1847-9286

www.jESE-online.org

Original scientific paper

\title{
Preparation of mesoporous carbon/polypyrrole composite materials and their supercapacitive properties
}

\author{
WU-JUN ZOU, SHAN-SHAN MO, SHUANG-LI ZHOU, TIAN-XIANG ZHOU, NAN-NAN XIA \\ and DING-SHENG YUAN $\bowtie$
}

Department of Chemistry, Jinan University, Guangzhou 510632, China

${ }^{\square}$ Corresponding Author: E-mail: tydsh@jnu.edu.cn; Tel.: +86-20-85220597; fax: +86-20-85221697

Received: March 18, 2011; Revised: May 19, 2011; Published: August 20, 2011

\begin{abstract}
We synthesized mesoporous carbons/polypyrrole composites, using a chemical oxidative polymerization and calcium carbonate as a sacrificial template. $\mathrm{N}_{2}$ adsorptiondesorption method, Fourier infrared spectroscopy, and transmission electron microscopy were used to characterize the structure and morphology of the composites. The measurement results indicated that as-synthesized carbon with the disordered mesoporous structure and a pore size of approximately $5 \mathrm{~nm}$ was uniformly coated by polypyrrole. The electrochemical behavior of the resulting composite was examined by cyclic voltammetry and cycle life measurements, and the obtained results showed that the specific capacitance of the resulting composite electrode was as high as $313 \mathrm{~F} \mathrm{~g} \mathrm{~g}^{-1}$, nearly twice the capacitance of pure mesoporous carbon electrode $\left(163 \mathrm{~F} \mathrm{~g}^{-1}\right)$. This reveals that the electrochemical performance of these materials is governed by a combination of the electric double layer capacitance of mesoporous carbon and pseudocapacitance of polypyrrole.
\end{abstract}

\section{Keywords}

Mesoporous carbon/polypyrrole composites; Chemical oxidation; Calcium carbonate; Sacrificial template; Specific capacitance; Pseudocapacitance

\section{Introduction}

Mesoporous carbon (MC) is one of the most important carbon materials with high surface area, uniform pore size, and good electric conductivity. During the past ten years, many efforts have been made to develop simple and efficient methods for the preparation of $M C$ materials and to improve their properties for various applications. Recently, one-step soft template methods for MC preparation have gradually replaced time-consuming and tedious two-step hard mesoporous 
silica templates, such as SBA-15, MCM-41, and MCM-48 [1,2]. The MCs and their composites are broadly applied to electrochemical capacitors [1,3], catalyst supports [4] and adsorbents [5,6], and magnetic separation [7]. Compared with mesopourous carbon materials, conducting polymers (CPs) possess pseudocapacitance, which is almost 10-100 times higher than the capacitance of electrochemical double-layer capacitors (EDLCs) [8]. Polypyrrole (PPy), one of CPs, has drawn a lot of attention for supercapacitor applications [9,10], mainly due to its oxidation-reduction properties, high conductivity in doped state, high specific capacitance, good environmental stability, and especially facile synthesis [11]. However, the shortcomings of CPs, such as low surface area and constrained power-output properties [12], markedly restrict their application to electrochemical capacitors. Hence, the most effective way is to use MC materials to improve the property of the CPs electrode. A new class of composite materials has originated from the combination of MCs and CPs [13]. Choi et al. introduced a conducting polymer layer into the pore surface of mesoporous carbon via vapor infiltration of a monomer and, by subsequent chemical oxidative polymerization, obtained mesoporous carbon-polypyrrole composites [14]. The maximum specific capacitance of these composites is $274.5 \mathrm{~F} \mathrm{~g}^{-1}$. Pacheco-Catalán et al. synthesized mesoporous carbon/conducting polymer composites by adsorption of different monomers (aniline, pyrrole, thiophene, and 3-methyltiophene) in the gas phase onto the carbon surface, followed by oxidative chemical polymerization [15]. The electrochemical performance of carbon/polypyrrole composites electrode showed that it had a low specific capacitance (maximum value: $83.8 \mathrm{~F} \mathrm{~g}^{-1}$ ) and stable cycle life in the potential range of 0 to $1 \mathrm{~V}$. However, all those materials showed low specific capacitance. Recently, we prepared mesoporous carbon by onestep method [16]. The obtained results revealed that MCs display good capacitive behavior with high reversibility and reproducibility due to their unique large mesopore size, which is favorable for fast ionic transport. However, the specific capacitance of MCs reaches only $163 \mathrm{~F} \mathrm{~g}^{-1}$, which limits their application to electric vehicles and high power electronic devices. In this study, we used PPy growth on the surface of MC via simple chemical oxidative polymerization with calcium carbonate as the sacrificial template to improve the capacitance of carbon materials. The resulting composite material combined double layer capacitance of $\mathrm{MC}$ with pseudocapacitance of PPy.

\section{Experimental}

\section{Chemicals}

Pyrrole monomer (98\%, Aldrich Chemical Co.) was distilled under reduced pressure, transferred into a refrigerator, and stored under nitrogen until further use. The diameter of nanoscale calcium carbonate was $80 \mathrm{~nm}$ and the BET surface area was $25 \mathrm{~m}^{3} \mathrm{~g}^{-1}$. Sodium 4-methyl benzene sulfonate (TsONa) was purchased from Sinopharm Chemical Reagent Co. Ltd, Shanghai, China. The other starting materials in this work were of analytical grade.

\section{Synthesis of mesoporous carbons/polypyrrole composites}

MCs were synthesized from F127/silica/butanol according to the procedure described previously [16]. Typically, $2 \mathrm{~cm}^{3}$ sulfuric acid (98wt\%) and $9.3 \mathrm{~cm}^{3}$ butanol (BuOH) were directly added into a clear solution containing $2.5 \mathrm{~g}$ F127 and $120 \mathrm{~g}$ deionized water at $318 \mathrm{~K}$. After stirring for $1.5 \mathrm{~h}, 5 \mathrm{~cm}^{3}$ tetraethyl orthosilicate (TEOS) was added, vigorously stirred at $318 \mathrm{~K}$ for $24 \mathrm{~h}$, and aged at $373 \mathrm{~K}$ for $24 \mathrm{~h}$. The F127/silica/butanol composites were collected by filtration and dried at room temperature for $12 \mathrm{~h}$ and at $433 \mathrm{~K}$ for $6 \mathrm{~h}$. Finally, the obtained composites were transferred into a tube furnace and carbonized under pure $\mathrm{N}_{2}$ atmosphere at $1123 \mathrm{~K}$ for $2 \mathrm{~h}$, followed by the treatment with diluted HF solution. The chemical oxidative polymerization of pyrrole was performed using a modified procedure reported previously [17]. First, $0.3 \mathrm{~g}$ TsONa, 0.5 $\mathrm{g} \mathrm{CaCO}_{3}, 25 \mathrm{~g} \mathrm{CaCl}_{2}, 20 \mathrm{~cm}^{3} \mathrm{C}_{2} \mathrm{H}_{5} \mathrm{OH}$, and $0.5 \mathrm{~g}$ Silica/Carbon were mixed into $40 \mathrm{~cm}^{3}$ deionized water with magnetic stirring under $\mathrm{N}_{2}$ atmosphere for $30 \mathrm{~min}$; the nanoscale $\mathrm{CaCO}_{3}$ served as a 
core, and TsONa was used as anionic surfactant. Then $0.3 \mathrm{~cm}^{3}$ pyrrole was added by a syringe. After $10 \mathrm{~min}, 40 \mathrm{~cm}^{3}$ of $0.02 \mathrm{~mol} \mathrm{dm}^{-3} \mathrm{FeCl}_{3}$ solution was slowly added as oxidant into the reaction vessel. The polymerization was carried out for $12 \mathrm{~h}$ in an ice-bath with magnetic stirring and maintained under $\mathrm{N}_{2}$ atmosphere. The mesoporous carbon/polypyrrole composite was filtered and rinsed several times with distilled water and ethanol to remove retained pyrrole monomer and oxidant. The as-synthesized powder was transferred into $\mathrm{HCl}$ solution for $\mathrm{CaCO}_{3}$ removal for $24 \mathrm{~h}$. The mixture was filtered and rinsed several times again with distilled water. Then the silica/carbon/PPy composite was treated by diluted HF solution to remove the silica and dried in vacuum at $333 \mathrm{~K}$ for $12 \mathrm{~h}$. The product was denoted as MP, containing an approximate MC:PPy weight ratio of 6:4. Under the influence of the Lewis acid $\mathrm{FeCl}_{3}$ and inhibition by abundant $\mathrm{CaCl}_{2}$, $\mathrm{CaCO}_{3}$ was dissolved, slowly releasing $\mathrm{CO}_{2}$, which contributed to the holes formation in the composite during the overflow process. Actually, $\mathrm{CaCO}_{3}$ as a core was the sacrificial template.

\section{Characterization}

The morphologies of $\mathrm{MC}$ and as-synthesized composite were examined using a high-resolution transmission electron microscopy (TEM, JEOL JEM-2100, $200 \mathrm{kV}$ ). Nitrogen sorption isotherms of samples were measured by a Micromertics TriStar 3000 analyzer at $77 \mathrm{~K}$. The FT-IR measurements on samples were performed using Nicolet 6700 FT-IR spectrometer. The electrochemical behavior of both MC and MP was investigated by cyclic voltammetry (CV) conducted on a $\mathrm{CHI} 660 \mathrm{~B}$ electrochemical workstation (ChenHua Instruments Co., Shanghai, China). The measurements were carried out in a standard three-electrode cell system. A Pt-foil modified by either MC or MP was used as the working electrode, saturated calomel electrode was used as the reference electrode, and a Pt-foil as the auxiliary electrode. The working electrodes were prepared by mixing active materials $(8 \mathrm{mg})$, acetylene black as a conductive reagent, and $5 \%$-Nafion as a binder (80:10:10 wt \%) and dispersed in absolute ethanol in ultrasonic bath. The dispersion was coated onto $\mathrm{Pt}$ foil drop by drop and then dried at $353 \mathrm{~K}$. The $\mathrm{CV}$ experiments were carried out in aqueous solution of $1 \mathrm{~mol} \mathrm{dm}^{-3} \mathrm{H}_{2} \mathrm{SO}_{4}$.

\section{Results and Discussion}

Fig. $1 \mathrm{a}$ and $1 \mathrm{~b}$ show the $\mathrm{N}_{2}$ adsorption-desorption isotherms and $\mathrm{BJH}$ pore size distribution of $M C$ and MP. The two samples are found to yield a type IV isotherm with a type H2 hysteresis loop near relative pressure of 0.50 in the desorption branch, which is associated with sharp capillary condensation taking place in mesopores [18].
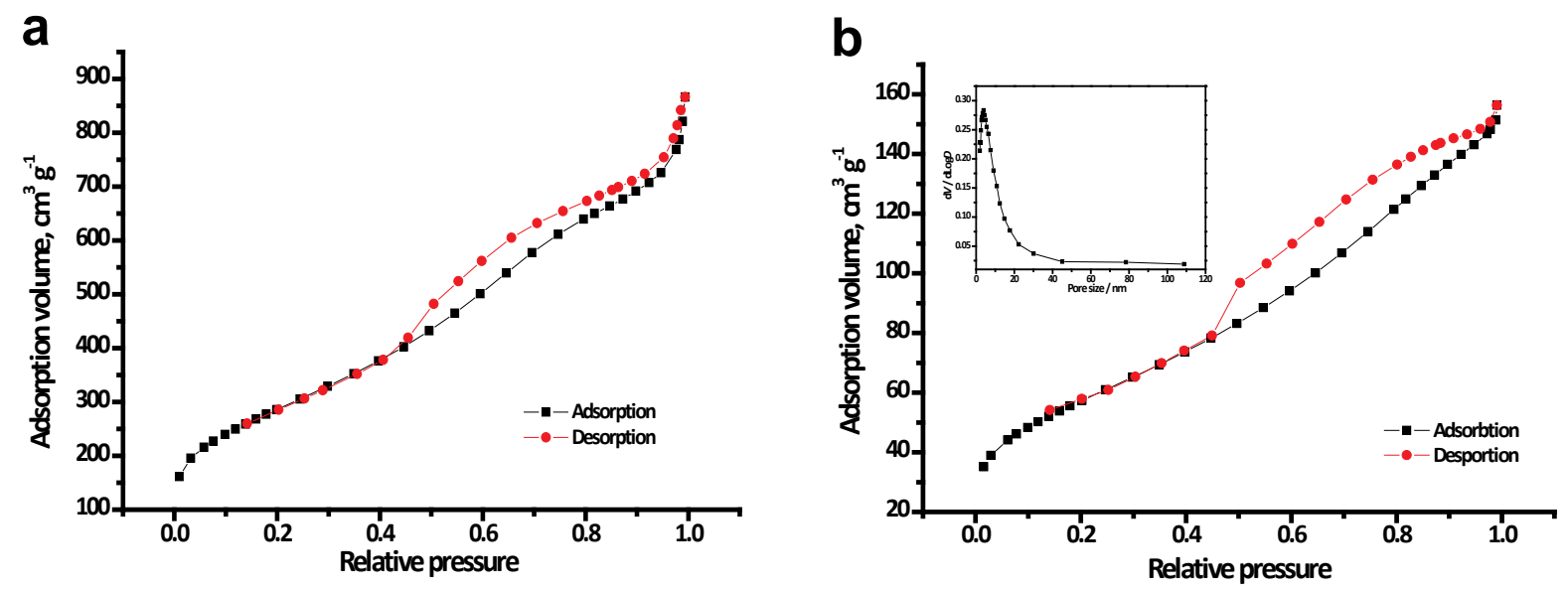

Figure 1. Nitrogen adsorption-desorption isotherms and BJH pore size distribution (inset) of a) $M C$ and b) $M P$. 
The results show that the mesoporous structure of MC was maintained after loading of PPy. However, BET surface area of MP was considerably lower. The specific surface areas of mesoporous carbon and MP were 1041 and $207 \mathrm{~m}^{2} \mathrm{~g}^{-1}$, respectively (Table 1). The decrease of specific surface area is mainly attributed to the mesopores of the support being partially covered or filled by PPy. Therefore, pore volume and average pore size also decrease from $1.18 \mathrm{~cm}^{3} \mathrm{~g}^{-1}$ and $5.2 \mathrm{~nm}$ to $0.22 \mathrm{~cm}^{3} \mathrm{~g}^{-1}$ and $4.9 \mathrm{~nm}$, respectively. This indicates that PPy was distributed evenly over the surface of MC.

In order to gain further insights into the structure of mesporous carbons, we investigated their appearance on the synthesized materials by TEM (Fig. 2). The disordered mesoporous size of MC with around $5 \mathrm{~nm}$, which is clearly visible in Fig. 2a, is in agreement with the data of the adsorption-desorption measurements (Fig. 1). Fig. 2b clearly shows the mesoporous structure of $\mathrm{MC}$ covered over with transparent films. In comparison with Fig. 2a, we may draw a conclusion that the transparent film is PPy and that it has been successfully loaded on the MC.
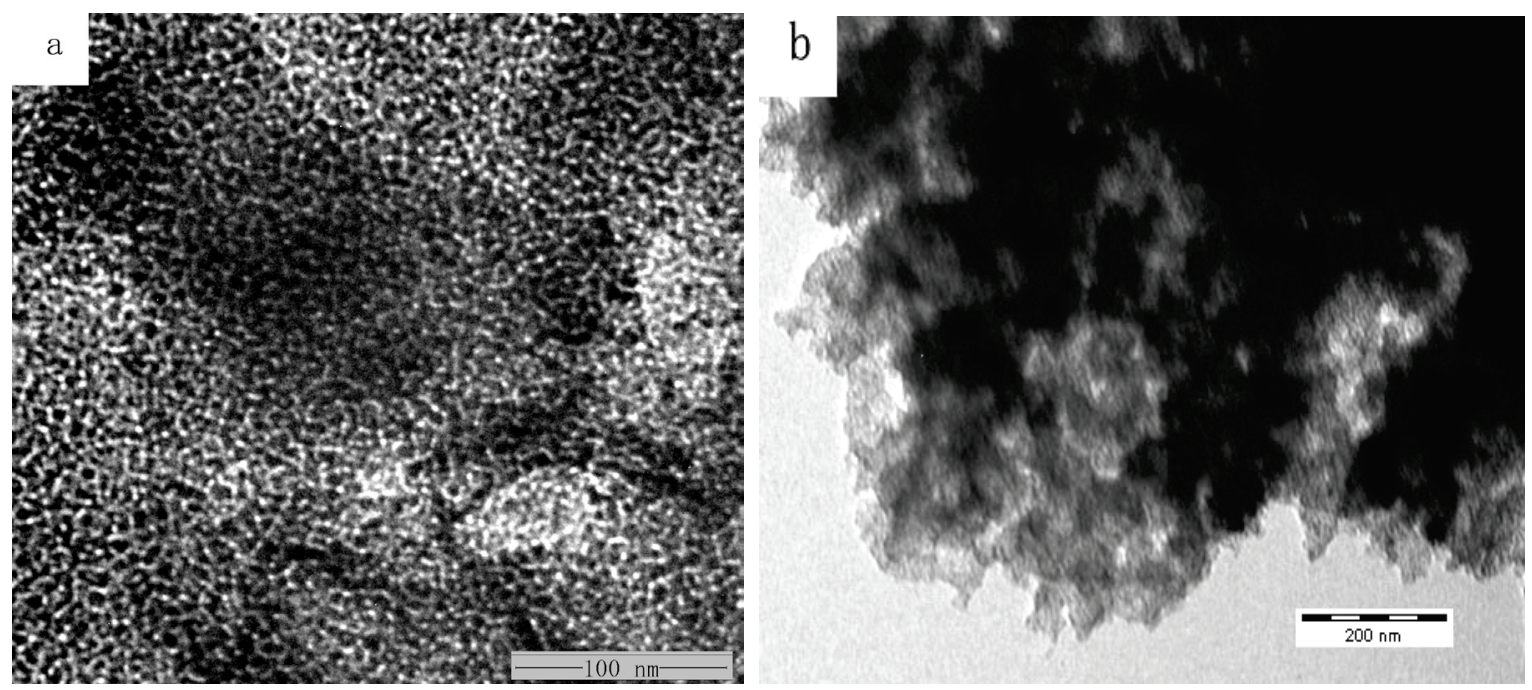

Figure 2. TEM images of a) $M C$ and b) $M P$.

The functional groups of MC, PPy, and MP are characterized by FTIR spectroscopy (Fig. 3). The characteristic peak at $3423 \mathrm{~cm}^{-1}$ is observed in the IR spectrum of $\mathrm{MC}$ and ascribed to $-\mathrm{OH}$. The small peaks at 2920 and $2850 \mathrm{~cm}^{-1}$ originate from the stretching vibrations of $\mathrm{C}-\mathrm{H}$ bond. The peaks at 1731,1632 , and $1402 \mathrm{~cm}^{-1}$ could be assigned to the stretching vibration in carboxyl groups and $C=O, C=C$, and $C-O$ bonds. The bands at 1537 and $1452 \mathrm{~cm}^{-1}$ in PPy and MP spectra are due to the typical pyrrole ring vibration of pure PPy and bands of $=\mathrm{C}-\mathrm{H}$ in plane vibration at 1298,1089 , and $1032 \mathrm{~cm}^{-1}$ [19]. The peaks at 3434 and $1631 \mathrm{~cm}^{-1}$ correspond to $\mathrm{N}-\mathrm{H}$ and $\mathrm{C}=\mathrm{C}$ stretching vibrations, respectively. The spectrum of MP is very similar to that of PPy, verifying that PPy has been successfully applied onto MC. However, the peak at $1632 \mathrm{~cm}^{-1}$ for $C=O$ disappeared due to the combination of MC and PPy. Similarly, the peak for $\mathrm{N}-\mathrm{H}$ stretching exhibits a red-shift phenomenon due to the interaction with the reactive hydroxyl functional groups [20].

Fig. 4 shows CVs of MC and MP in $1 \mathrm{~mol} \mathrm{dm}^{-3} \mathrm{H}_{2} \mathrm{SO}_{4}$ at different scan rates. $\mathrm{CVs}$ of MC electrode contain redox peaks and deviate from the rectangular shape (Fig. 4a). With increasing scan rates, the redox current evidently increases, indicating that it has good rate capability. FTIR spectra confirm the existence of the abundant functional groups, for example $\mathrm{C}=\mathrm{O}$ and $\mathrm{O}-\mathrm{H}$ bonds, on the surface of MC. These groups are supposed to remarkably improve the hydrophilicity and wettability of the surface of $\mathrm{MC}$ and are beneficial for the aqueous electrochemical capacitors. The redox peaks might originate from the transformation of the $\mathrm{O}-\mathrm{H}$ bond of $\mathrm{MC}$ into the $\mathrm{C}=\mathrm{O}$ and vice versa during charge and discharge processes. In addition, the $\mathrm{C}=\mathrm{O}$ bond of $\mathrm{MC}$ interacts with the $\mathrm{H}^{+}$to become $-\mathrm{OH}$ in the reduced state, which would be re-oxidized into $\mathrm{C}=\mathrm{O}$ during the discharge. 


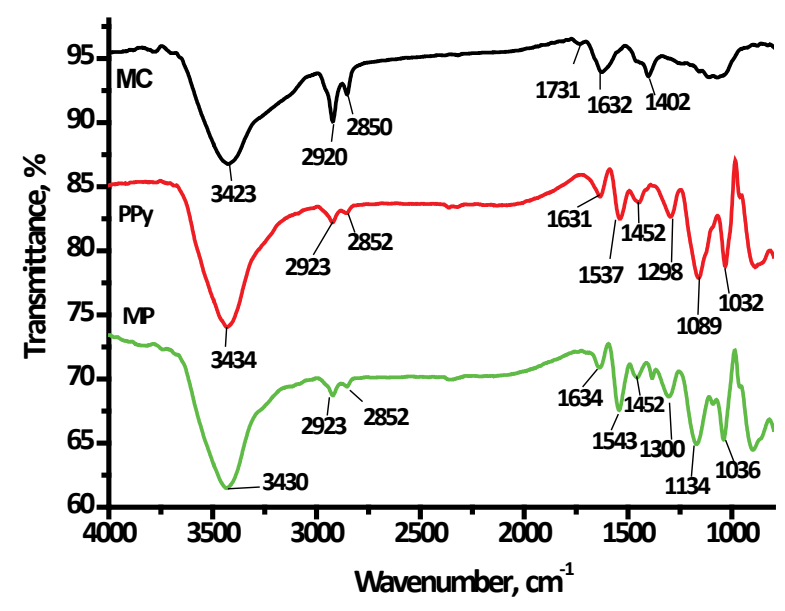

Figure 3. FT-IR spectra of MC, PPy and MP.

However, the CVs of MP present a steep increase in the current range from 0.0 to $0.1 \mathrm{~V}$, which is an important behavior in supercapacitors [14], as shown in Fig. 4b. CV curves of the composites do not exhibit redox peaks as pronouncedly as in the case of MC. This is because the $\pi$-bonded surface of the MC may interact strongly with the conjugated structure of PPy, especially through the pyrrole ring [21], or $\mathrm{N}-\mathrm{H}$ of PPy can interact with the reactive hydroxyl functional groups of $\mathrm{MC}$ [20].
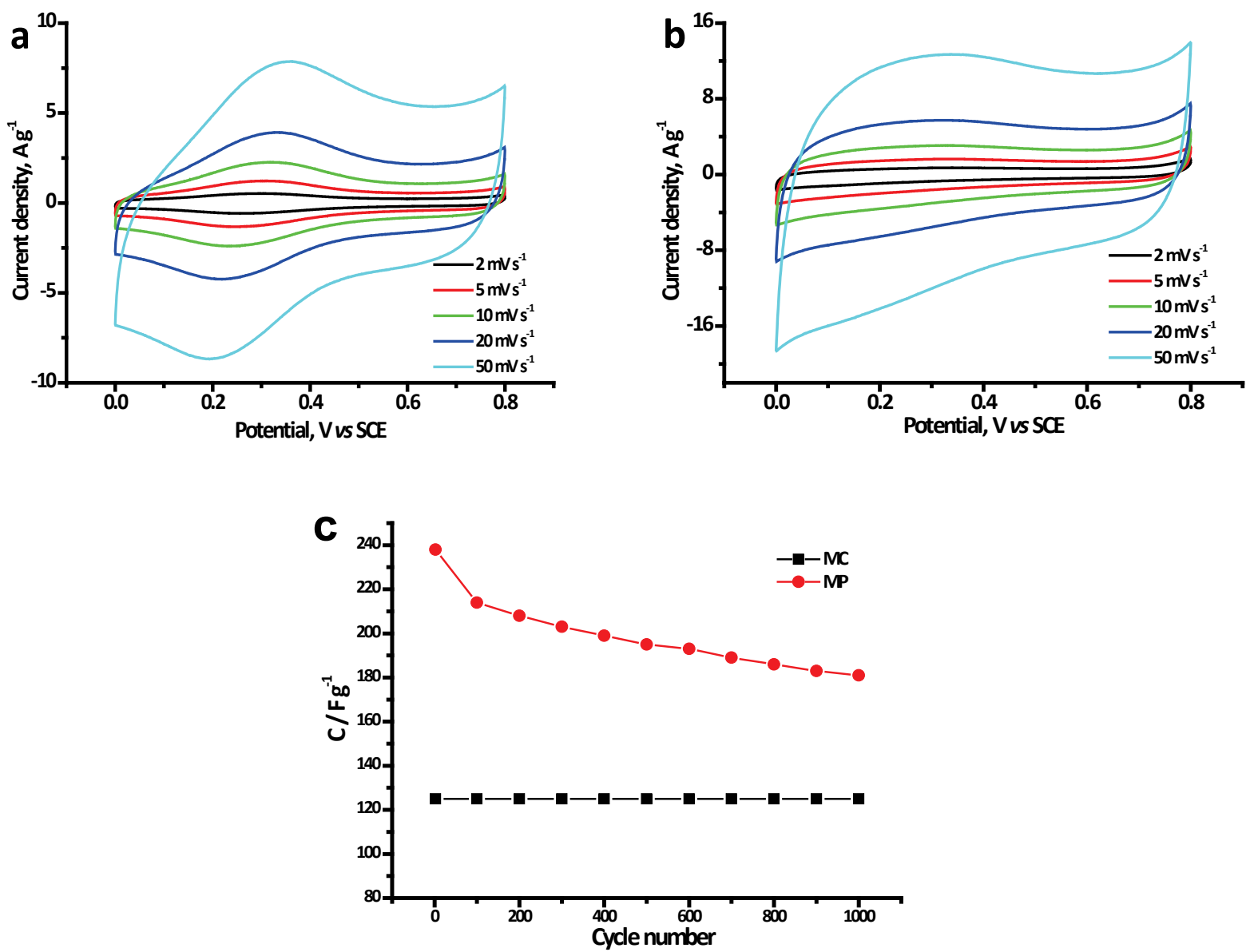

Figure 4. (Vs of a) MC and b) MP in $1 \mathrm{~mol} \mathrm{dm}^{-3} \mathrm{H}_{2} \mathrm{SO}_{4}$ electrolyte at different scan rates; c) cycle life of MC and MP in $1 \mathrm{~mol} \mathrm{dm}^{-3} \mathrm{H}_{2} \mathrm{SO}_{4}$ electrolyte at the scan rate of $20 \mathrm{mV} \mathrm{s}^{-1}$. 
The gravimetric specific capacitance $(C)$ of electrode is calculated according to the Eq. (1) from charge-discharge data of CVs:

$$
C=\frac{Q}{W V}=\frac{\int i \mathrm{~d} t}{W \Delta V}
$$

where $i, W$ and $V$ are the voltammetric current, the mass of active materials, and the total potential of electrochemical window, respectively. The calculated specific capacitances are listed in Table 1. The maximum specific capacitance of MP reaches as high as $313 \mathrm{~F} \mathrm{~g}^{-1}$ at the scan rate of $2 \mathrm{mV} \mathrm{s}^{-1}$, which is nearly twice the specific capacitance of $\mathrm{MC}\left(163 \mathrm{~F} \mathrm{~g}^{-1}\right)$. Although the surface area of MC dramatically decreases due to the coverage of PPy, leading to the EDLC loss, the pseudocapacitance from the Faradic reaction on the PPy contributes much more to the total capacitance, leading to a higher specific capacitance of MP. Due to the different synthesis methods and electrolytes and measured potential windows, it is difficult to compare our results with those reported in the literatures. Therefore, for comparison purpose, we synthesized the PPy using the same method and measured the electrochemical properties in $1 \mathrm{~mol} \mathrm{dm}^{-3} \mathrm{H}_{2} \mathrm{SO}_{4}$. The specific capacitance of pure PPy was $328.4 \mathrm{~F} \mathrm{~g}^{-1}$ at a scan rate of $2 \mathrm{mV} \mathrm{s}^{-1}$. If the contribution of pure MC and pure PPy were calculated, the total was only $229 \mathrm{~F} \mathrm{~g}^{-1}$. However, in this study, we obtained a higher result that reached $313 \mathrm{~F} \mathrm{~g}^{-1}$, revealing the intensely synergetic effect between $\mathrm{MC}$ and PPy. Fig. 4c shows a cycle life of $\mathrm{MC}$ and $\mathrm{MP}$ in $1 \mathrm{~mol} \mathrm{dm}^{-3} \mathrm{H}_{2} \mathrm{SO}_{4}$ electrolyte at scan rate of $20 \mathrm{mV} \mathrm{s}^{-1}$. The specific capacitance of MP drops from $238 \mathrm{~F} \mathrm{~g}^{-1}$ down to $181 \mathrm{~F} \mathrm{~g}^{-1}$ after 1000 cycles, corresponding to a $23.9 \%$ loss.

Table 1. Pore structure parameters of the MC and MP and the specific capacitances of MC and MP electrodes calculated from CVs in $1 \mathrm{~mol} \mathrm{dm}^{-3} \mathrm{H}_{2} \mathrm{SO}_{4}$ electrolyte

\begin{tabular}{|c|c|c|c|c|c|c|c|c|}
\hline \multirow{2}{*}{ Sample } & \multirow{2}{*}{$\begin{array}{c}\text { Surface area } \\
\mathrm{m}^{2} \mathrm{~g}^{-1}\end{array}$} & \multirow{2}{*}{$\begin{array}{c}\text { Pore volume } \\
\mathrm{cm}^{3} \mathrm{~g}^{-1}\end{array}$} & \multirow{2}{*}{$\begin{array}{c}\text { Pore size } \\
\mathrm{nm}\end{array}$} & \multicolumn{5}{|c|}{$C / \mathrm{Fg}^{-1}$} \\
\hline & & & & $2 \mathrm{mV} \mathrm{s}^{-1}$ & $5 \mathrm{mV} \mathrm{s}^{-1}$ & $10 \mathrm{mV} \mathrm{s}^{-1}$ & $20 \mathrm{mV} \mathrm{s}^{-1}$ & $50 \mathrm{mV} \mathrm{s}^{-1}$ \\
\hline $\mathrm{MC}$ & 1041 & 1.18 & 5.2 & 163 & 150 & 139 & 125 & 103 \\
\hline MP & 207 & 0.22 & 4.9 & 313 & 281 & 261 & 238 & 203 \\
\hline
\end{tabular}

\section{Conclusions}

MC/PPy composites were successfully synthesized using a chemical method of oxidative polymerization. The resulting modified electrode showed some properties similar to the combination of the double layer capacitance of MC and pseudocapacitance of PPy. The results obtained by cyclic voltammetry demonstrated that the specific capacitance of the MP electrode was as high as $313 \mathrm{~F} \mathrm{~g}^{-1}$ compared to $163 \mathrm{~F} \mathrm{~g}^{-1}$ of $\mathrm{MC}$ electrode. In conclusion, it seems that the MP is a promising electrode material in supercapacitor field.

Acknowledgements: The study was financially supported by the National Natural Science Foundation of China (20876067 and 21031001) and the Fundamental Research Funds for the Central Universities (21609203).

\section{References}

[1] J. Lee, S. Yoon, T. Hyeon, S.M. Oh and K.B. Kim, Chem. Commun. 21 (1999) 2177-2178

[2] K.T. Lee, X.L. Ji, M. Rault and L.F. Nazar, Angew. Chem. Int. Ed. 121 (2009) 5661-5665

[3] J.X. Chen, N.N. Xia, T.X. Zhou, S.X. Tan, F.P. Jiang and D.S. Yuan, Int. J. Electrochem. Sci. 4 (2009) 1063-1073

[4] S.H. Joo, S.J. Choi, I. Oh, J. Kwak, Z. Liu, O. Terasaki and R. Ryoo, Nature 412 (2001) 169-172

[5] A. Vinu, C. Streb, V. Murugesan and M. Hartmann, J. Phys. Chem. B 107 (2003) 8297-8299 
[6] X.W. Liu, L. Zhou, J.W. Li, Y. Sun, W. Su and Y.P. Zhou, Carbon 44 (2006) 1386-1392

[7] J.W. Lee, S.M. Jin, Y.S. Hwang, J.G. Park, H.M. Park and T. Hyeon, Carbon 43 (2005) 25362543

[8] C. Peng, S.W. Zhang, D. Jewell and G.Z. Chen, Prog. Nat. Sci. 18 (2008) 777-788

[9] X.Q. Lin and Y.H. Xu, Electrochim. Acta 53 (2008) 4990-4997

[10] S.W. Woo, K. Dokko and K. Kanamura, J. Power Sources 185 (2008) 1589-1593

[11] J. Wang, Y.L. Xu, X. Chen and X.F. Sun, Compos. Sci. Technol. 67 (2007) 2981-2985

[12] W. Xing, X. Yuan, S.P. Zhuo and C.C. Huang, Polym. Adv. Technol .20 (2009) 1179-1182

[13] W. Xing, S. P. Zhuo, H.Y. Cui and Z.F. Yan, Mater. Letters 61 (2007) 4627-4630

[14] M. Choi, B. Lim and J. Jang, Macromol. Res. 16 (2008) 200-203

[15] D.E. Pacheco-Catalán, M.A. Smit, E. Morales, Int. J. Electrochem. Sci. 6 (2011) 78-90

[16] X. Yan, H.H. Song and X.H. Chen, J. Mater. Chem. 19 (2009) 4491-4494

[17] F.P. Jiang, T.X. Zhou, S.X. Tan, Y. Zhu, Y.L. Liu and D.S. Yuan, Int. J. Electrochem. Sci. 4 (2009) 1541-1547

[18] K. S. W Sing, D. H. Everett, R. A. W. Haul, L. Moscou, R. A. Pierotti, J. Rouqoerol and T. Simieniewska, Pure Appl. Chem. 57 (1985) 603

[19] W. Chen, X.W. Li, G.Xue, Z.Q. Wang and W.Q. Zou, Appl. Surf. Sci. 218 (2003) 215-221

[20] L. Ding, C. Hao, X.J. Zhang and H.X. Ju, Electrochem. Commun. 11 (2009) 760-763

[21] Y.C. Zhao, X.L. Yang, J.N. Tian, F.Y. Wang and L. Zhan, J. Power Sources 195 (2010) 46344640

(C) 2011 by the authors; licensee IAPC, Zagreb, Croatia. This article is an open-access article distributed under the terms and conditions of the Creative Commons Attribution license (http://creativecommons.org/licenses/by/3.0/) (cc) EY 